\title{
Neonatal Mortality is Modulated by Gestational Age, Birthweight and Fetal Heart Rate Abnormalities in the Low Resource Setting in Tanzania - a Five Year Review 2015-2019
}

\author{
Aisa Shayo \\ Kilimanjaro Christian Medical Centre Moshi \\ Pendo Mlay \\ Kilimanjaro Christian Medical Centre Moshi \\ Emily Ahn \\ Weill Cornell Medicine \\ Hussein Kidanto
}

Aga Kahn University

Michael Espiritu

Weill Cornell Medicine

Jeffrey M. Perlman ( $\Delta$ jmp2007@med.cornell.edu )

Weill Cornell Medicine

\section{Research Article}

Keywords: Neonatal mortality, Fetal Heart Rate Abnormalities, Birth Asphyxia, Helping Babies Breathe, Bag mask ventilation, Hypothermia

Posted Date: November 9th, 2021

DOI: https://doi.org/10.21203/rs.3.rs-1039876/v1

License: (c) (i) This work is licensed under a Creative Commons Attribution 4.0 International License. Read Full License 


\section{Abstract \\ Background}

Neonatal mortality (NM) remains a significant problem in low resource settings. Birth asphyxia (BA) and prematurity contribute significantly to NM. The study objectives were to determine first, the overall NM as well as yearly neonatal mortality rate from 2015 to 2019 . Second, the impact of decreasing GA (<37 weeks) and BW (<2500 grams) on NM. Third, the contribution of intrapartum and delivery room (DR) factors and in particular fetal heart rate abnormalities (FHRT) on $\mathrm{NM}<7$ days.

\section{Methods}

Retrospective cohort study. Labor and delivery room data were obtained from 2015 to 2019 and included BW, GA, fetal heart rate (FHRT) abnormalities, bag mask ventilation (BMV) during resuscitation, initial temperature, antenatal steroids use. Outcome was binary i.e. either death $<7$ days or survival. Analysis included $t$ tests, odds ratios (OR) and multiple logistic regression

\section{Results}

The overall neonatal mortality rate was $18 / 1000$ livebirths over the five years. NM was significantly higher for newborns $<37$ versus $\geq 37$ weeks, OR 10.5 ( $p<0.0001)$ and $B W<2500$ versus $\geq 2500 \mathrm{~g}$ OR 9.9 $(p<0.0001)$. For infants $<1000 \mathrm{~g} /<28$ weeks, the neonatal mortality rate was $\sim 588 / 1000$ livebirths. Variables associated with NM included BW - odds of death decreased by 0.55 for every $500 \mathrm{~g}$ increase in weight, by 0.89 for every week increase in GA, NM increased 6.8-fold with BMV, 2.6-fold with abnormal FHRT, 2.2 fold with no antenatal corticosteroid (ACS), 2.6-fold with moderate hypothermia (all <0.0001).

\section{Conclusion}

NM rates was predominantly modulated by decreasing BW and GA, with smaller/ less mature newborns 10 -fold more likely to die. NM in term newborns is strongly associated with FHRT abnormalities and when coupled with respiratory depression suggests BA. In smaller newborns, lack of ACS and moderate hypothermia were additional contributing factors. A composite perinatal approach is essential to achieve a sustained reduction in NM.

\section{Introduction}

It is estimated that 2.7 million newborns die annually worldwide, which contributes to approximately $45 \%$ of under- 5 child mortality. ${ }^{1,2}$ The first day and especially the first hour is critical to newborn survival, with the highest risk of intrapartum-related neonatal deaths (birth asphyxia (BA)) occurring during this 
period. ${ }^{1,2}$ In addition to BA (30 to $35 \%$ ), prominent causes include prematurity/low birth weight (25 to 30 $\%)$, presumed infection ( 30\%) and congenital anomalies (8-15\%). ${ }^{3}$ An estimated 1.3 million babies are reported to be "fresh stillborn" (FSB), suggestive of an intrapartum demise, shortly before delivery. 4,5 The Helping Babies Breathe (HBB) program was piloted in Tanzania in 2009, at a time where the neonatal mortality rate (NMR) approximated $25.3 / 1000$ live births (LB). This study was associated with a 47 percent reduction in early neonatal mortality (NM) ( $\leq 24$ hours) and a 24 percent reduction in FSB. ${ }^{6}$ By 2015, more than 13000 providers had been trained in HBB throughout Tanzania. ${ }^{7}$ In 2015 a pilot study of a premature care bundle was implemented to mothers in preterm labor (28 to 34 weeks gestational age (GA)) and their newborns. ${ }^{8}$ At the completion of the study in 2017, the care bundle was associated with a 26 percent reduction in NM. By 2019, the overall NM in Tanzania had decreased to 20.3/1000 live births. ${ }^{9}$

Kilimanjaro Christian Medical Center (KCMC) participated in both studies (HBB and the care bundle) and provides an opportunity to assess the impact of both interventions on $\mathrm{NM}<7$ days over time. There are data to indicate that NM is strongly influenced by GA and/or birth weight (BW) as well as variables during labor and the delivery room. ${ }^{10-18}$ Moreover many of the prior studies have not examined NM as a function of time. This is relevant to KCMC, since a premature care bundle was introduced in that institution in 2015 and completed in 2017. ${ }^{8}$ Furthermore, most prior studies have not examined the impact of a progressive decrease in both BM and GA but rather as either $<37$ weeks or $<2500$ grams BW. The study objectives were to determine first, the overall NM as well as yearly neonatal mortality rate from 2015 to 2019. Second, to determine the impact of decreasing GA ( $<37$ weeks) and BW ( $<2500$ grams) on NM and third, the contribution of intrapartum and delivery room (DR) factors and in particular fetal heart rate abnormalities (FHRT) on NM $<7$ days.

\section{Methods}

This was a retrospective study of prospectively collected labor and delivery room data of newborns delivered at KCMC, a zonal referral University Teaching Hospital serving over 15 million people in Northern Tanzania for the period January 2015 to December 2019.

Management of Mothers during Labor using Fetal Heart Rate (FHRT)

During labor, FHRT is monitored by intermittent auscultation using a fetoscope, or intermittently/continuously with Doppler, which included Moyo (Laerdal Medical). Moyo is a novel Doppler machine that uses a 9-crystal sensor, which rapidly detects the FHRT. ${ }^{19}$ Cardiotocography (CTG) is utilized for continuous external fetal monitoring (CEFM) in high-risk pregnancy cases. The midwife interprets the majority of the fetoscope and Doppler signals. The obstetrician interprets the CEFM. Fetal scalp blood gases or fetal stimulation is not done.

Indications for Cesarean Section (CS) include those considered absolute, i.e. contracted pelvis, placenta previa, and relative including abruption placentae with unfavorable cervix, fetal distress, and malpresentation. 
The CS rate ranges between 34 to 44 percent. The approximate number of annual deliveries ranges from 4000 to 4500 .

Management of the Newborn in the Delivery Room

Midwives are the primary providers at the majority of spontaneous vaginal deliveries and are trained in HBB to manage resuscitation of the newborn. A self-inflation bag without positive end expiratory pressure is used for ventilation.

Management of Newborns in the Neonatal Care Area

High-risk newborns are admitted to a neonatal care unit with a capacity of 62 beds. The management of premature infants with respiratory distress includes continuous positive airway pressure (CPAP) (Pumani - Rice $360^{\circ}$ Institute for Global Health Technologies) ${ }^{20}$ where available; there are only two CPAP machines. Intubation and mechanical ventilation is not available. Additional interventions include intravenous antibiotics as indicated, and Kangaroo mother care to stable newborns.

\section{Data Monitoring:}

A dedicated computer close to the labor ward has been used for data entry since 2009. Data collection includes core and desired elements developed for the initial HBB rollout and expanded following implementation of the Care Bundle in 2015. Data retrieved included BW, GA, singletons/twins, fetal heart rate (FHRT) abnormalities on arrival, during and prior to delivery (abnormal defined as $<120$ or $>160$ beats/minute), labor complications (including pre-eclampsia/eclampsia, malpresentation, arrest of descent), mode of delivery (vaginal, cesarean section, breech), bag mask ventilation (BMV)), one and five minute Apgar scores, use of a care bundle (maternal and neonatal antibiotics where indicated, antenatal corticosteroids (ACS) to mothers of GA 28 to 34 weeks, maintaining infant temperature following delivery). ${ }^{8}$ Outcome was either survival or death $\leq 7$ days. Data analysts (AS, PM) and a technical consultant (JMP) analyzed the data.

\section{Definitions}

BA was defined as a 5-minute Apgar score $<7$ and lack of spontaneous respirations after birth. GA was based on self-report of the last normal menstrual period and/or fundal height, the latter the distance from symphysis pubis to the uterine fundus in the middle of the woman's abdomen, as is the standard practice in Tanzania. ${ }^{21}$ Moderate preeclampsia was defined as a blood pressure $>140 / 90 \mathrm{mmHg}$ with associated proteinuria and severe pre-eclampsia as a blood pressure $\geq 160 / 110 \mathrm{mmHg}$ with specific signs and symptoms. Neonatal mortality was death within the first seven days following birth. Birth weight (BW) cutoff for live births was $\geq 750$ grams. Fresh stillbirth (FSB) was defined as an Apgar score $=0$ at both 1 and 5 minutes with intact skin and suspected death during labour/delivery, and of birth weight $>1000$ grams. 


\section{Data Analysis}

Analysis has been performed using Statistical Package for Social Sciences (SPSS) 22; and included descriptive statistics, chi square analysis, t tests and odds ratio (OR) calculations. OR were calculated from the logistic regression analysis. Outcome was binary, i.e. death versus survived $\leq 7$ days. A multiple logistic regression was developed to estimate effects of BW, GA, referral versus inborn, gender, preeclampsia, multiples, mode of delivery (vaginal versus CS), abnormal FHRT on admission and prior to delivery, BMV, moderate hypothermia (initial temperature $<36^{\circ} \mathrm{C}$ ), ACS administration and $\mathrm{NM} \leq 7$ days. Data was analyzed for the entire cohort followed by subgroup analysis for infants, $<37$ weeks versus $\geq 37$ weeks or $<2500 \mathrm{~g}$ versus $\geq 2500 \mathrm{~g}$. All data are presented as mean \pm standard deviation unless as otherwise stated.

Ethical Considerations: This report reflects a retrospective review of data already collected. As such no patient consent was obtained for the data review. The data had been prospectively obtained as part of implementation of a care bundle (2015-2017) which had received ethical clearance from the National Institute of Medical Research of Tanzania. ((NIMR/HQ/R/R.8c/Vol.I/1156). These studies were performed in accordance with relevant guidelines and regulations. This study has been previously published (see reference 8). Approval for extension of ethical clearance from the National Institute of Medical Research of Tanzania specifically for continued retrospective data review was subsequently obtained. (NIMR/HQ/R.8a/Vol.IX/1887).

\section{Results}

General

Between January 2015 through December 2019 there were 21125 deliveries of which 20246 (96\%) were live births; 369 died (1.8\%), 305 (1.4\%) were FSB and 205 (1\%) were macerated stillbirths. The overall NMR was $18 / 1000$ live births (range 14.7 to 23 ); for infants $<37$ weeks GA the NMR was $81 / 1000$ (range 63 to 104 ) and $8 / 1000$ for infants $\geq 37$ weeks GA (range 3.6 to 10.2). (Fig. 1) Comparing 2015 to subsequent years, the overall NMR was comparable to all subsequent years. (Fig. 1) (Table 1) For newborns $\geq 37$ weeks, NMR was comparable for years 2015 through 2018 but less in $2019(p=0.0006)$. (Table 1) For newborns <37 weeks, NMR was comparable for all years relative to 2015. (Table 1) Comparing year 2018 to 2019, the overall NM decreased significantly (OR $0.6295 \%$ confidence interval (Cl) $0.45-0.85)(p=0.0003)$ as well as for newborns $\geq 37$ weeks (OR 0.45(0.23-0.87) $(p=0.01)$ and $<37$ weeks (OR 0.57) $(\mathrm{Cl} 0.39-0.84)(\mathrm{p}=0.004)$. 
Table 1

Comparison of Overall Neonatal Mortality Rates, Infants $\geq 37$ weeks and $<37$ weeks for Years 20152019

\begin{tabular}{|c|c|c|c|}
\hline \multirow[t]{2}{*}{ Year } & Overall Difference & $\geq 37$ weeks & $<37$ weeks \\
\hline & OR (95\% Cl) p value & OR (95\% Cl) p value & OR $(95 \% \mathrm{Cl}) \mathrm{p}$ value \\
\hline 2015 vs 2016 & $1.02(0.73-1.42) p=0.88$ & $1.01(0.64-1.60) p=0.93$ & $0.96(0.59-1.56) p=0.14$ \\
\hline 2015 vs 2017 & $0.92(0.66-1.28) p=0.64$ & $0.5(0.35-1.01) p=0.55$ & $1.02(0.65-1.58) p=0.92$ \\
\hline 2015 vs 2018 & $1.32(0.98-1.77) p=0.06$ & $0.77(0.47-1,26) p=0.31$ & $1.26(0.84-1.88) p=0.25$ \\
\hline 2015 vs 2019 & $0.82(0.69-1.12) p=0.22$ & $0.35(0.19-0.63) p=0.006$ & $0.72(0.48-1.08) p=0.12$ \\
\hline
\end{tabular}

NM was significantly higher for newborns $<37$ versus $\geq 37$ weeks, i.e. $232 / 2854$ (8.1\%) vs $137 / 17763$ $(0.8 \%)$ odds ratio (OR) 10.5 (95\% Cl 8.5-13) ( $\mathrm{p}<0.0001)$ respectively, and for $\mathrm{BW}<2500$ versus $\geq 2500 \mathrm{~g}$, i.e. $240 / 3192(7.5 \%)$ versus $129 / 17054(0.7 \%)$ (OR 9.9 (95\% Cl 7.9 to 12.3$)(p<0.0001)$ respectively. The contribution of lesser BW and GA to overall NM is shown in Fig. 2 and 3 . Specifically for infants $<1000 \mathrm{~g}$ or $<28$ weeks, NM was 587 and 588 per 1000 live births respectively. NM progressively decreased with increasing BW and GA, but was still substantial for BW 2000 to $25000 \mathrm{~g}$ at 22/1000 and 35 to 36 weeks at $19 / 1000$. It was lowest for infants $\geq 2500 \mathrm{~g}$ or $\geq 37$ weeks at 7 per 1000 live births (Fig. 2, 3)

Characteristics of Newborns who Died compared to Survivors

Entire Cohort

Infants who died versus survivors were of a lesser BW $(p<0.0001)$ and GA $(p<0.0001)$. (Table 2$)$ Infants who died versus survivors had a significantly lower initial temperature $(p<0.0001)$, were 1.3-fold more likely to be males $(p=0.009), 2.1$-fold to be of a twin set $(p<0.0001), 1.68$-fold to be associated with a maternal transfer $(p<0.0001)$, six-fold more likely to have any labor complications and specifically preeclampsia/eclampsia ( $<0.0001), 20$-fold more likely to exhibit an abnormal FHRT on admission $(p<0.0001)$ and 33 -fold prior to delivery $(p<0.0001), 1.9$-fold more likely be delivered via CS $(p<0.0001)$, 1.8-fold to be delivered breech ( $p=0.01), 161$-fold more likely to have an Apgar score $<7$ at 5 minutes $(p<0.0001), 116$-fold more likely to receive BMV $(p<0.0001)$ and 11.9-fold more likely to exhibit moderate hypothermia $(p<0.0001)$. 
Table 2

Perinatal Characteristics of Infants who Survived versus those who Died for the overall population 20152019

\begin{tabular}{|lllll|}
\hline Characteristics & $\begin{array}{l}\text { Survived } \\
\mathrm{n}=\mathbf{2 0 2 5 0}\end{array}$ & $\begin{array}{l}\text { Died } \\
\mathrm{n}=369\end{array}$ & p value & OR (95\% Cl) \\
\hline Birth Weight (g) & $3105 \pm 612$ & $2108 \pm 954$ & $<0.0001$ & \\
\hline Gestational Age (weeks) & $38.4 \pm 2.2$ & $34.1 \pm 4.5$ & $<0.0001$ & \\
\hline Initial Temperature $\left({ }^{\circ} \mathrm{C}\right)$ & $36.3 \pm 0.31$ & $35.67 \pm 0.37$ & $<0.0001$ & \\
\hline Gender (Males) & $11020(54 \%)$ & $226(61 \%)$ & 0.009 & $1.3(1.1-1.6)$ \\
\hline Plurals & $1008(5 \%)$ & $37(10 \%)$ & $<0.0001$ & $2.1(1.5-3.9)$ \\
\hline Maternal referral & $8432(42 \%)$ & $201(54 \%)$ & $<0.0001$ & $1.7(1.3-2.0)$ \\
\hline Any Labor Complication & $9816(48.5 \%)$ & $313(85 \%)$ & $<0.0001$ & $6.1(4.5-8.1)$ \\
\hline Eclampsia/Preeclampsia & $712(3.5 \%)$ & $58(15.7 \%)$ & $<0.0001$ & $5.1(3.8-6.7)$ \\
\hline Breech Presentation & $585(2.9 \%)$ & $19(5.1 \%)$ & 0.01 & $1.8(1.1-2.9)$ \\
\hline Abnormal FHRT before Delivery & $1303(6.4 \%)$ & $256(69.8 \%)$ & $<0.0001$ & $33.2(26.4-41.8)$ \\
\hline CS Delivery & $8675(44 \%)$ & $220(62 \%)$ & $<0.0001$ & $1.9(1.6-2.4)$ \\
\hline Apgar at 1 minute & $9(10)$ & $4(9)$ & $<0.0001$ & \\
\hline Apgar at 5 minutes & $10(10)$ & $6(10)$ & $<0.0001$ & \\
\hline 5 minute Apgar Score $<7$ & $216(1.1 \%)$ & $234(63.4 \%)$ & $<0.0001$ & $161(125-206)$ \\
\hline Moderate Hypothermia $\left(<36^{\circ} \mathrm{C}\right)$ & $301 / 1195(25 \%)$ & $96 / 120(80 \%)$ & $<0.0001$ & $11.9(7.4-18.8)$ \\
\hline Bag/Mask Ventilation in DR & $1734(8.6 \%)$ & $338(91.6 \%)$ & $<0.0001$ & $116(80-168)$ \\
\hline OR= Odds Ratio Cl = Confidence Interval, FHRT=Abnormal Fetal Heart Rate; DR = Delivery Room, & \\
\hline Apgar Score numbers are presented as Median and Interquartile range & & \\
\hline
\end{tabular}

Multivariate Logistic Regression Analysis

When controlling for other predictors BW, GA, abnormal FHRT, and BMV contributed significantly to mortality. Specifically, for BW the odds of dying decreased 0.71 for each $500 \mathrm{~g}$ increase in BW, and it decreased 0.93 for each one-week increase in GA. The odds of dying increased four-fold with an abnormal FHRT prior to delivery $(p<0.0001)$, and 32-fold with receipt of BMV $(p<0.0001)$. There were too many missing temperature values for this variable to be included in the analysis. Characteristics of Newborns who Died compared to Survivors < 37 weeks EGA (Table 3 ) Infants who died versus survivors were of a significantly lesser BW and GA $(p<0.0001)$, had a lower initial temperature $(p<0.0001)$, were 11.7-fold more likely to exhibit an abnormal FHRT prior to delivery $(p<0.0001), 2.2$-fold more likely to 
receive $0-2$ doses as opposed to $3-4$ doses of ANS ( $p<0.0001), 42$-fold more likely to be administered BMV $(p<0.0001)$, and 7.2 -fold more likely to exhibit moderate hypothermia $(p<0.0001)$. Additional significant differences are shown in Table 3.

Table 3

Perinatal Characteristics of Infants who Survived versus those who Died $<37$ weeks

\begin{tabular}{|c|c|c|c|c|}
\hline Characteristics & $\begin{array}{l}\text { Survived } \\
n=2619\end{array}$ & $\begin{array}{l}\text { Died } \\
n=232\end{array}$ & $\mathrm{p}$ value & OR $(95 \% \mathrm{Cl})$ \\
\hline Birth Weight (g) & $2162 \pm 560$ & $1513 \pm 560$ & $<0.0001$ & \\
\hline Gestational Age (weeks) & $33.93 \pm 2.36$ & $31.17 \pm 2.85$ & $<0.0001$ & \\
\hline Initial Temperature $\left({ }^{\circ} \mathrm{C}\right)$ & $36.03 \pm 0.32$ & $35.67 \pm 0.37$ & $<0.0001$ & \\
\hline Gender (Males) & $1349(51.4 \%)$ & $142(61.2 \%)$ & 0.004 & $1.50(1.13-1.96)$ \\
\hline Plurals & $408(15.6 \%)$ & $35(15.1 \%)$ & 0.85 & \\
\hline Referred & $1202(45.8 \%)$ & $123(53.0 \%)$ & 0.03 & $1.3(1.02-1.74$ \\
\hline Any Labor Complications & $1830(69.9 \%)$ & $205(88.7 \%)$ & $<0.0001$ & $3.4(2.23-5.15)$ \\
\hline Eclampsia/Preeclampsia & $358(13.7 \%)$ & $51(22.0 \%)$ & 0.001 & $1.8(1.28-2.48)$ \\
\hline Breech & $95(3.6 \%)$ & $14(6 \%)$ & 0.06 & $1.7(0.96-3.04)$ \\
\hline Abn FHRT before Delivery & $491(14.9 \%)$ & $156(67.2 \%)$ & $<0.0001$ & $11.7(8.72-15.72)$ \\
\hline Cesarean Section Delivery & $1397(55.3 \%)$ & $141(63.5 \%)$ & 0.01 & $1.4(1.06-1.87)$ \\
\hline Apgar Score at $1 \mathrm{~min}$ & $8(9)$ & $4(9)$ & $<0.0001$ & \\
\hline Apgar Score at $5 \mathrm{~min}$ & $10(10)$ & $6(10)$ & $<0.0001$ & \\
\hline Apgar Score at 5 minutes $<7$ & $108(4.1 \%)$ & $140(60.3 \%)$ & $<0.0001$ & $\begin{array}{l}35.4(25.57- \\
49.08)\end{array}$ \\
\hline $\begin{array}{l}\text { Moderate Hypothermia } \\
\left(<36^{\circ} \mathrm{C}\right)\end{array}$ & $\begin{array}{l}292 / 1148 \\
(25.4 \%)\end{array}$ & $\begin{array}{l}94 / 118 \\
(79.7 \%)\end{array}$ & $<0.0001$ & $7.2(11.49-18.18)$ \\
\hline Bag mask ventilation in DR & $741(28.3 \%)$ & 218 (94.4\%) & $<0.0001$ & $\begin{array}{l}42.5(24.14- \\
74.89)\end{array}$ \\
\hline ANS $0-2$ vs, 3-4 doses & 1815 (69.2\%) & $193(83.2 \%)$ & $<0.0001$ & $2.20(1.54-3.14)$ \\
\hline
\end{tabular}

Multivariate Logistic Analysis

Five variables were significantly associated with NM. When controlling for other predictors, the odds of death decreased by 0.55 for every $500 \mathrm{~g}$ increase in BW and by 0.89 -fold for every one week increase in 
GA. The odds of dying increased 6.8-fold with BMV application ( $p<0.0001), 2.6$-fold with an abnormal FHRT prior to delivery $(p<0.0001)$, and 2.6-fold with moderate hypothermia $(<0.0001)$.

Characteristics of Newborns who Died compared to Survivors $\geq 37$ weeks GA (Table 4)

Infants $\geq 37$ weeks $G A$ who died versus those who survived were of significant lesser BW $(p<0.0001)$ but comparable GA ( $p=0.58)$. Infants were 50 -fold more likely to have an abnormal FHRT prior to delivery $(p<0.0001), 118$-fold more likely to be administered BMV. There were too few newborns in this GA group with a temperature measurement to include in the analysis.

Table 4

Perinatal Characteristics of Infants who Survived versus those who Died $\geq 37$ weeks

\begin{tabular}{|lllll|}
\hline Characteristics & $\begin{array}{l}\text { Survived } \\
\mathbf{n = 1 7 6 1 7}\end{array}$ & $\begin{array}{l}\text { Died } \\
\mathbf{n}=138\end{array}$ & p value & OR (95\% Cl) \\
\hline Birth Weight (g) & $3245 \pm 482$ & $3102 \pm 571$ & 0.001 & \\
\hline Gestational Age (weeks) & $39.15 \pm 1.08$ & $39.09 \pm 1.33$ & 0.58 & \\
\hline Male & $9669(54.9 \%)$ & $84(61.3 \%)$ & 0.13 & $1.3(0.92-1.84)$ \\
\hline Plurals & $600(3.4 \%)$ & $2 / 135(1.5 \%)$ & 0.33 & \\
\hline Referred & $7230(41.1 \%)$ & $78(56.9 \%)$ & 0.002 & $1.9(1.35-2.67)$ \\
\hline Any Labor Complications & $7964(45.3 \%)$ & $108(78.8 \%)$ & $<0.0001$ & $4.4(2.97-6.75)$ \\
\hline Eclampsia/Preeclampsia & $363(2.0 \%)$ & $7(5.1 \%)$ & 0.02 & $2.6(1.22-5.62)$ \\
\hline Breech & $490(2.8 \%)$ & $5(3.6 \%)$ & 0.53 & \\
\hline Abnormal FHRT before Delivery & $912(5.2 \%)$ & $100(73.5 \%)$ & $<0.0001$ & $50.8(34.6-74.9)$ \\
\hline Cesarean Section Delivery & $7276(41.9 \%)$ & $79(60.3 \%)$ & $<0.0001$ & $2.1(1.48-2.99)$ \\
\hline Apgar at 1 min & $9(10)$ & $4(10)$ & $<0.0001$ & \\
\hline Apgar at 5 min & $10(10)$ & $6(10)$ & $<0.0001$ & \\
\hline Apgar Score at 5 min <7 & $108(0.8 \%)$ & $94(66.6 \%)$ & $<0.0001$ & $354(235-532)$ \\
\hline Bag Mask Ventilation in the DR & $992(5.6 \%)$ & $120(87.6 \%)$ & $<0.0001$ & $118(71-197)$ \\
\hline Hypothermia not included because of very small numbers & & \\
\hline FHRT= Fetal Heart Rate; DR= Delivery Room; Apgar score numbers presented as Median and & & & \\
\hline Interquartile range & & & & \\
\hline
\end{tabular}

Multivariate Logistic Analysis 
Only an abnormal FHRT prior to delivery and BMV were significantly associated with NM. The odds of dying increased 7.3-fold with an abnormal FHRT $(p<0.0001)$ and 42 -fold $(p<0.0001)$ with BMV.

Outcome as a Function of Birth Weight <2500 grams (Table 5)

Infants who died versus those who survived were of a lesser BW $(p<0.0001)$ and GA $(p<0.0001)$, had a lower initial temperature $(p<0.0001)$, were 1.7 -fold more likely to receive $0-2$ as opposed to 4 doses of ANS ( $p=0.002), 9.8$-fold more likely to have an abnormal FHRT upon admission $(p<0.0001), 13.6$-fold more likely to exhibit an abnormal FHRT prior to delivery ( $p<0.001), 48.7$-fold more likely to be administered BMV $(p<0.001)$, and 11-fold more likely to exhibit moderate hypothermia $(p<0.0001)$. (Table 5)

Table 5

Perinatal Characteristics of Infants who Survived versus those who Died $\leq 2500 \mathrm{~g}$

\begin{tabular}{|c|c|c|c|c|}
\hline Characteristics & $\begin{array}{l}\text { Survived } \\
\mathrm{n}=3187\end{array}$ & $\begin{array}{l}\text { Died } \\
n=241\end{array}$ & p value & OR $(95 \% \mathrm{Cl})$ \\
\hline Birth Weight (grams) & $2072 \pm 385$ & $1507 \pm 504$ & $<0.0001$ & \\
\hline Gestational Age (weeks) & $35.18 \pm 3.02$ & $31.59 \pm 3.3$ & $<0.0001$ & \\
\hline Initial Temperature $\left({ }^{\circ} \mathrm{C}\right)$ & $36.03 \pm 0.31$ & $35.67 \pm 0.37$ & $<0.0001$ & \\
\hline Males & $1562(49 \%)$ & $147(61 \%)$ & 0.0003 & $1.6(1.24-2.12)$ \\
\hline Plurals & $681(21.4 \%)$ & $36(14.9 \%)$ & 0.01 & $0.6(0.4-0.93)$ \\
\hline Referred & $1516(47.6 \%)$ & $128(53.1 \%)$ & 0.09 & $1.2(0.96-1.62)$ \\
\hline Any Labor Complications & $2178(68.5 \%)$ & $210(87.5 \%)$ & $<0.0001$ & $3.2(2.18-4.76)$ \\
\hline Eclampsia/Preeclampsia & $394(12.4 \%)$ & $52(21.6 \%)$ & $<0.0001$ & $1.9(1.41-2.70)$ \\
\hline Breech & $118(3.7 \%)$ & $14(5.8 \%)$ & 0.10 & $1.6(0.91-2.84)$ \\
\hline Abnormal FHRT before Delivery & $432(13.6 \%)$ & $164(68 \%)$ & $<0.0001$ & $13.6(10.2-18.1)$ \\
\hline Cesarean Section Delivery & $1640(53.5 \%)$ & $140(60.9 \%)$ & 0.03 & $1.3(1.03-1.78)$ \\
\hline Apgar at $1 \mathrm{~min}$ & $8(9)$ & $4(9)$ & $<0.0001$ & \\
\hline Apgar at $5 \mathrm{~min}$ & $10(10)$ & $6(10)$ & $<0.0001$ & \\
\hline 5 Minute Apgar Score $<7$ & $110(3.5 \%)$ & $147(61.0 \%)$ & $<0.0001$ & $43.7(31.7-60.3)$ \\
\hline Moderate Hypothermia $<36^{\circ} \mathrm{C}$ & $294 / 1138(25 \%)$ & $95 / 119(79 \%)$ & $<0.0001$ & $11.3(7.1-18.2)$ \\
\hline Bag/Mask Ventilation in DR & $793(25 \%)$ & $226(94 \%)$ & $<0.0001$ & $48.7(28.5-84)$ \\
\hline Antenatal Steroids $0-2$ doses & $2394(75 \%)$ & $202(83 \%)$ & 0.002 & $1.72(1.2-2.4)$ \\
\hline
\end{tabular}

FHRT= Fetal Heart Rate; DR= Delivery Room; Apgar score numbers are Median and Interquartile range 
Multivariate Logistic Regression Analysis

When controlling for other predictors, six variables were significantly associated with NM. These included BW, where the odds of dying decreased by 0.57 for every $500 \mathrm{~g}$ increase in weight and by 0.86 for every one-week increase in GA. The odds of dying was 1.6-fold higher in male infants $(p=0.004)$, increased 1.6fold with an abnormal FHRT upon admission ( $p<0.01)$, 2.7-fold with an abnormal FHRT prior to delivery $(p<0.0001)$ and 14.7-fold in infants administered BMV $(p<0.0001)$.

Newborns $>2500$ grams (Table 6)

Infants who died versus those who survived were of comparable BW but lesser GA ( $p=0.04)$, were 26 -fold more likely to have an abnormal FHRT upon admission ( $p<0.0001), 48.8$-fold more likely exhibit an abnormal FHRT prior to delivery $(p<0.0001)$, and 119 -fold more likely be more likely to be administered $B M V$ in the DR.

Table 6

Perinatal Characteristics Associated with Outcome for Newborns $>2500 \mathrm{~g}$

\begin{tabular}{|lllll|}
\hline Characteristics & $\begin{array}{l}\text { Survived } \\
\mathbf{n = 1 7 0 5 8}\end{array}$ & $\begin{array}{l}\text { Died } \\
\mathbf{n}=128\end{array}$ & p value & OR (95\% Cl) \\
\hline Birth Weight (g) & $3298 \pm 426$ & $3238 \pm 433$ & 0.11 & \\
\hline Gestational Age (weeks) & $39.08 \pm 0.42$ & $38.86 \pm 1.94$ & 0.04 & \\
\hline Males & $9454(55.4 \%)$ & $49(61.7 \%)$ & 0.15 & $1.29(0.91-1.86)$ \\
\hline Plurals & $327(1.9 \%)$ & $1(0.8 \%)$ & 0.36 & $0.40(0.05-2.89)$ \\
\hline Referred & $6913(41 \%)$ & $73(57 \%)$ & 0.0002 & $1.95(1.37-2.76)$ \\
\hline Any Labor Complications & $7634(44.8 \%)$ & $103(80.5 \%)$ & $<0.0001$ & $5.08(3.27-7.87)$ \\
\hline Eclampsia/Preeclampsia & $317(1.9 \%)$ & $6(4.6 \%)$ & 0.03 & $2.59(1.13-5.95)$ \\
\hline Breech & $467(2.7 \%)$ & $5(3.9 \%)$ & 0.40 & $1.44(0.58-3.55)$ \\
\hline Abnormal FHRT before Delivery & $871(5.1 \%)$ & $92 / 127(72.4 \%)$ & $<0.0001$ & $48.8(32.9-72.52)$ \\
\hline Cesarean Section Delivery & $7032(41.8 \%)$ & $80(65 \%)$ & $<0.0001$ & $2.59(1.78-3.75)$ \\
\hline Apgar at 1 min & $9(10)$ & $4(9)$ & $<0.0001$ & \\
\hline Apgar at 5 min & $10(10)$ & $5(10)$ & $<0.0001$ & \\
\hline 5 Minute Apgar Score <7 & $106(0.6 \%)$ & $87(68 \%)$ & $<0.0001$ & $339(223-515)$ \\
\hline Bag/Mask Ventilation in the DR & $941(5.5 \%)$ & $112(87.5 \%)$ & $<0.0001$ & 119 (71- 203) \\
\hline $\begin{array}{l}\text { Hypothermia not included because of small numbers. FHRT= Fetal Heart Rate; DR= Delivery Room; } \\
\text { Apgar score numbers are Median and Interquartile range }\end{array}$ & & \\
\hline
\end{tabular}


Multivariate Logistic Regression Analysis (>2500 grams)

When holding other variables constant only BMV and FTHR prior to delivery had a significant effect on mortality. The odds of dying were 44.8 -fold higher $(p<0.0001)$ for those newborns resuscitated with BMV and 7.0 -fold higher $(p<0.0001)$ with an abnormal FHRT prior to delivery.

\section{Discussion}

The findings in this report indicate that the overall NMR for the five years was approximately $18 / 1000$ live births and ranged from 14 to 23/1000 LB. NM was strongly influenced by both GA and BW. Thus, for newborns $<37$ weeks, NM was approximately 81/1000 live births (range 63 to 104) and $\geq 37$ weeks $8 / 1000$ live births (range 3 to 10.2). More specifically, when categorized as either by GA, <37 versus $\geq 37$ weeks or $\mathrm{BW}<2500$ versus $\geq 2500$ grams, the less mature or smaller newborns as opposed to the larger more mature newborns were approximately 10 -fold more likely to die. Furthermore, NM increased markedly as a function of decreasing GA and/or BW. Thus, the highest NM was for infants $<28$ weeks GA or $<1000 \mathrm{~g} \mathrm{BW}$ with a rate of approximately $588 / 1000$ live births i.e. $\sim 75$ fold more likely to die as opposed to neonates $>37$ weeks GA. Conversely, the NM was lowest for those $\geq 37$ weeks or $\geq 2500$ grams of approximately $7 / 1000$ live births. For the entire cohort, the odds of dying deceased 29 percent for every $500 \mathrm{~g}$ increase in $\mathrm{BW}$, and 11 percent for each week increase in GA. Additional contributors to NM included an abnormal FHRT on admission and prior to delivery, as well as the application of BMV during resuscitation in the delivery room. For newborns of GA $<37$ weeks moderate hypothermia also significantly increased the likelihood of NM.

When examined over time, the overall NMR as well as that of newborns $<37$ weeks demonstrated no significant year-to-year differences when comparing 2015 to subsequent years. However, for newborns $\geq 37$ weeks, there was a significant decrease in NM in 2019 when compared to 2015. (Figure 1) Interestingly, the higher but non-significant NMR for infants $<37$ weeks in 2018 was followed by a significant reduction in both in 2019. (Figure 1) This reduction may reflect the fact that by 2019 the care bundle had been fully implemented. The highest NM was in the smallest newborns, i.e. $<1000$ grams or $<28$ weeks where close to 60 percent died. Factors contributing to death in these infants likely include respiratory distress particularly in the absence of ACS, and an increased risk for moderate hypothermia which has been shown to be an independent risk factor for mortality. ${ }^{22,23}$ In addition there was limited respiratory support; only two CPAP machines were available during the five years.

These data are novel in that NM was expressed as an overall NMR, as well as a function of decreasing GA and BW. The wide disparity in NM identified, offers an opportunity for more targeted interventions. For infants $>37$ weeks, NM was approximately $8 / 1000$ livebirths which was 10 fold less than mortality for those neonates $<37$ weeks and 75 fold lower than for neonates $<1000 \mathrm{~g}$ and/or 28 weeks GA.. The pathway to death in the more mature newborns appears to be mediated via intrapartum factors identified by an abnormal FHRT on admission and prior to delivery, coupled with respiratory depression at birth, as indicated by a 5 -minute Apgar score $<7$ and the requirement for BMV. ${ }^{24}$ The constellation of findings is 
consistent with the World Health Organization definition of BA. ${ }^{3,25}$ For those newborns $<37$ weeks and/or $<2500$ grams, in addition to an abnormal FHRT and BMV, not receiving ANS, and presenting with initial moderate hypothermia were risk factors associated with increased likelihood of NM.

These findings indicate that strategies to reduce NM need to be initiated upon arrival in the delivery room with a major focus on FHRT monitoring. At KCMC, the predominant method of detecting an abnormal FHRT is via the intermittent use of a fetoscope, less often using Doppler. Recently Moyo a novel Doppler machine has been used more frequently to monitor FHRT. ${ }^{19}$ Recognition of an abnormal FHRT and prompt intervention may be of particular importance in reducing NM. ANS administration to mothers of GA 28 to 34 weeks has been recently shown to reduce NM. ${ }^{26}$ Upon delivery instituting the steps contained in the HBB within the Golden Minute and instituting interventions as needed, including MBV and avoiding hypothermia are essential strategies. Procurement of additional CPAP machines is important to treat respiratory distress, as needed. ${ }^{27}$ Additional training of physicians and nurses who specialize in management of very preterm babies and use these more advanced strategies is essential. ${ }^{27}$

The study has several limitations. First, we did not example the contribution of antenatal factors, which have been found in other studies to contribute to NM. ${ }^{10,11,13,14}$ In this regard it is notable that a maternal referral was associated with a 1.7 fold increased likelihood of death. Second, the report represents a single center, and the findings may not be generalizable to other regions of Tanzania, or other low resource countries. Third, the categorization of FHRT as abnormal does not describe the specific abnormality. Fourth, any labor complications (e.g. malpresentation, arrest of descent) as a grouping was significantly associated with NM. However, other than for pre-eclampsia, these complications were relatively infrequent to be able to demonstrate significant individual differences in outcome. Fifth, it was not possible to accurately identify the contribution of small for gestational age to overall NM. Sixth, the putative causes of death was not available.

In conclusion, these data indicate that NMR is predominantly modulated by decreasing BW and GA, with smaller and less mature 10-fold more likely to die as compared to the larger more mature newborn. The pathway to death in the term newborn appears to be triggered by intrapartum factors including labor complications, specifically pre-eclampsia and FHRT abnormalities. These observations coupled with respiratory depression at birth is highly suggestive of BA. In smaller babies in addition to the above, a lack of ANS exposure and moderate hypothermia appear to be additional contributory factors. To achieve a sustained reduction in NM, a composite perinatal approach is essential initiated upon admission to the delivery suite.

Figure 1: Overall, $<37$ weeks, and $\geq 37$ weeks Gestational Age Neonatal Mortality per 1000 Live Births 2015-2019

Figure 2: Mortality Per 1000 Live Births as a Function of Birth Weight

\section{Abbreviations}


$\mathrm{BA}=$ Birth Asphyxia

FSB $=$ Fresh Still Birth

$\mathrm{HBB}=$ Helping Babies Breathe

NM $=$ Neonatal Mortality

NMR $=$ Neonatal Mortality Rate

$\mathrm{GA}=$ Gestational Age

BW $=$ Birth Weight

$\mathrm{KCMC}=$ Kilimanjaro Christian Medical Centre

CEFM $=$ Continuous electronic fetal monitoring

FHRT = Fetal Heart Rate

CS $=$ Cesarean Section

CPAP = Continuous Positive Airway Pressure

ACS $=$ Antenatal Corticosteroids

SPSS $=$ Statistical Package of Social Sciences

$\mathrm{OR}=$ Odds Ratio

$\mathrm{Cl}=$ Confidence Interval

$\mathrm{BMV}=$ Bag Mask Ventilation

\section{Declarations}

Ethics approval and consent to participate: The pilot implementation of HBB in 2009 as well as implementation of the care bundle received ethical clearance from the National Institute of Medical Research of Tanzania. (NIMR/HQ/R.8a/Vol.IX/1887). This was a retrospective review of the data. No consent was sought

Consent for Publication: Not Applicable.

Availability of Data and Materials: The datasets used and/or analyzed during the current study are available from the corresponding author on reasonable request.

Competing Interests: 
Drs. Aisa Shayo, Pendo Mlay, Emily Ahn, Hussein Kidanto, Michael Espiritu and Jeffrey Perlman have no competing interests to disclose.

Funding: The study was supported in part by a grant from Bloomberg Philanthropies, who had no role in the design of the study, data collection, analysis and interpretation of data, or writing of the manuscript.

\section{Author's Contributions:}

AS helped conceptualize and design the study, helped with the collection of data, drafted the initial manuscript, reviewed and revised the manuscript and approved the final version.

PM helped conceptualize helped with the collection of data and data analysis, drafted the initial manuscript, and reviewed and revised the manuscript and approved the final version.

EA helped with interpretation of the data, revising it critically for important intellectual content of the manuscript, approved the final version.

HK helped with interpretation of the data, revising it critically for important intellectual content of the manuscript, approved the final version.

ME helped with interpretation of the data, revising it critically for important intellectual content of the manuscript, approved the final version.

JP helped conceptualize and design the study, helped with the data analysis, drafted the initial manuscript, reviewed and revised the manuscript, approved the final version.

All authors read and approved the final manuscript.

Acknowledgements: Not applicable.

\section{References}

1. UN Inter-agency Group for Child Mortality Estimation. Levels \& Trends in Child Mortality. Report 2019. Available from: https://www.unicef.org/media/60561/file/UN-IGME-child-mortality-report-2019.pdf. Last accessed May 18, 2020.

2. Wang H, Liddell CA, Coates MM, Mooney MD, Levitz, CE, Schumacher AE, et al. Global, regional, and national levels of neonatal, infant, and under-5 mortality during 1990-2013: a systematic analysis for the global Burden of Disease Study 2013. Lancet. 2014;384(9947):957-79.

3. Lawn JE, Blencowe H, Oza S, You D, Lee AC, Waiswa P, et al. Every Newborn: progress, priorities, and potential beyond survival. Lancet. 2014;384(9938):189-205.

4. Blencowe H, Cousens S, Jassir FB, Say L, Chou D, Mathers C, et al. National, regional, and worldwide estimates of stillbirth rates in 2015, with trends from 2000: systematic analysis. Lancet Global Health.2016;4(2):e98-108. 
5. Lawn JE, Blencowe H, Waiswa P, Amousou A, Mathers C, Hogan D, et al. Stillbirths: rates, risk factors, and acceleration towards 2030. Lancet. 2016;387(10018):587-603.

6. Msemo G, Massawe A, Mmbando D, Rusibamayila N, Manji K, Kidanto HL, et al. Newborn Mortality and Fresh Stillbirth Rates in Tanzania After Helping Babies Breathe Training. Pediatrics. 2013;131(2):e 353-60.

7. Arlington L, Kairuki AK, Isangula KG, Meda RA, Thomas E, Temu A, et al. Implementation of "Helping Babies Breathe": A Three-Year Experience in Tanzania. Pediatrics. 2017;139(5):e20162132.

8. Massawe A, Kidanto HL, Moshiro R, Majaliwa E, Chacha F, Shayo A, et al. A care bundle including antenatal corticosteroids reduces preterm infant mortality in Tanzania a low resource country. PLoS ONE. 2018;13(3):e0193146.

9. United Republic of Tanzania - Neonatal Mortality Rate. Knoema World Data Atlas. https://knoema.com/atlas/United-Republic-of-Tanzania/Neonatal-mortality-rate. Last Accessed May $14,2021$.

10. de Souza S, Duim E, Nampo FK. Determinants of neonatal mortality in the largest international border of Brazil: a case-control study. BMC Public Health. 2019;19(1):1304. doi: 10.1186/s12889019-7638-8. PMID: 31619198; PMCID: PMC6796356.

11. Kibria GMA, Burrowes V, Choudhury A, Sharmeen A, Ghosh S, Mahmud A, Kc A. Determinants of early neonatal mortality in Afghanistan: an analysis of the Demographic and Health Survey 2015. Global Health. 2018;14(1):47. doi: 10.1186/s12992-018-0363-8. PMID: 29743085; PMCID: PMC5944060.

12. Manjavidze T, Rylander C, Skjeldestad FE, Kazakhashvili N, Anda EE. Incidence and Causes of Perinatal Mortality in Georgia. J Epidemiol Glob Health. 2019;9(3):163-168. doi: 10.2991/jegh.k.190818.001. PMID: 31529933.

13. Kidus F, Woldemichael K, Hiko D. Predictors of neonatal mortality in Assosa zone, Western Ethiopia: a matched case control study. BMC Pregnancy Childbirth. 2019;19(1):108. doi: 10.1186/s12884-0192243-5. PMID: 30925903; PMCID: PMC6441179.529933; PMCID: PMC7310824.

14. Lona Reyes JC, Pérez Ramírez RO, Llamas Ramos L, Gómez Ruiz LM, Benítez Vázquez EA, Rodríguez Patino V. Neonatal mortality and associated factors in newborn infants admitted to a Neonatal Care Unit. Arch Argent Pediatr. 2018;116(1):42-48. English, Spanish. doi: 10.5546/aap.2018.eng.42. PMID: 29333811.

15. Garces AL, McClure EM, Pérez W, Hambidge KM, Krebs NF, et al The Global Network Neonatal Cause of Death algorithm for low-resource settings. Acta Paediatr. 2017;106(6):904-911. doi: 10.1111/apa.13805. Epub 2017 Apr 5. PMID: 28240381; PMCID: PMC5425300.

16. Al-Sheyab NA, Khader YS, Shattnawi KK, Alyahya MS, Batieha A. Rate, Risk Factors, and Causes of Neonatal Deaths in Jordan: Analysis of Data From Jordan Stillbirth and Neonatal Surveillance System (JSANDS). Front Public Health. 2020;8:595379. doi: 10.3389/fpubh.2020.595379. PMID: 33194998; PMCID: PMC7661434.

17. Ersdal HL, Mduma E, Svensen E, Perlman J. Birth asphyxia: a major cause of early neonatal mortality in a Tanzanian rural hospital. Pediatrics. 2012;129(5):e1238-43. doi: 10.1542/peds.2011-3134. Epub 
2012 Apr 16. PMID: 22508912.

18. Moshiro R, Perlman JM, Kidanto H, Kvaløy JT, Mdoe P, Ersdal HL. Correction: Predictors of death including quality of positive pressure ventilation during newborn resuscitation and the relationship to outcome at seven days in a rural Tanzanian hospital. PLoS ONE. 2018;13(9):e0204084. https://doi.org/10.1371/journal.pone.0204084

19. Kamala BA, Ersdal HL, Dalen I, Abeid MS, Ngarina MM, Perlman JM, et al. Implementation of a novel continuous fetal Doppler (Moyo) improves quality of intrapartum fetal heart rate monitoring in a resource-limited tertiary hospital in Tanzania: An observational study. PLoS One. 2018;13(10):e0205698. doi: 10.1371.

20. Mwatha AB, Mahande M, Olomi R, John B, Philemon R. Treatment outcomes of Pumani bubble-CPAP versus oxygen therapy among preterm babies presenting with respiratory distress at a tertiary hospital in Tanzania-Randomised trial. PLoS One. 2020;15(6):e0235031. doi: 10.1371/journal.pone.0235031.

21. White LJ, Lee SJ, Stepniewska K, Simpson JA, Dwell SLM, Arunjerdja, et al. Estimation of gestational age from fundal height: a solution for resource-poor settings. Journal of the Royal Society Interface. 2012;9(68):503-10. doi: 10.1098/rsif.2011.0376

22. Laptook A, Salhab W, Bhaskar B, and The Neonatal Research Network. Admission temperature of low birth weight infants: predictors and associated morbidities.Pediatrics. 2007;119:e643-9.

23. Mullany LC, Katz J, Khatry SK, LeClerq SC, Darmstadt GL, Tielsch JM. Risk of mortality associated with neonatal hypothermia in southern Nepal. Arch Pediatr Adolesc Med. 2010;64(7):650-656.

24. Langli Ersdal H, Mduma E, Svensen E, Sundby J, Perlman J. Intermittent detection of fetal heart rate abnormalities identify infants at greatest risk for fresh stillbirths, birth asphyxia, neonatal resuscitation, and early neonatal deaths in a limited-resource setting: a prospective descriptive observational study at Haydom Lutheran Hospital. Neonatology. 2012;102(3):235-42.

25. Moshiro R, Mdoe P, Perlman JM. A Global View of Neonatal Asphyxia and Resuscitation. Front Pediatr. 2019;7:489. doi: 10.3389/fped.2019.00489.

26. WHO ACTION Trials Collaborators, Oladapo OT, Vogel JP, Piaggio G, Nguyen MH, Althabe F, et al. Antenatal Dexamethasone for Early Preterm Birth in Low-Resource Countries. N Engl J Med. 2020;383(26):2514-2525. doi: 10.1056/NEJMoa2022398. PMID: 33095526; PMCID: PMC7660991.

27. van den Heuvel M, Blencowe $H$, Mittermayer K, Rylance S, Couperus A, Heikens GT, et al. Introduction of bubble CPAP in a teaching hospital in Malawi. Ann Trop Paediatr. 2011;31(1):59-65.

\section{Figures}


110

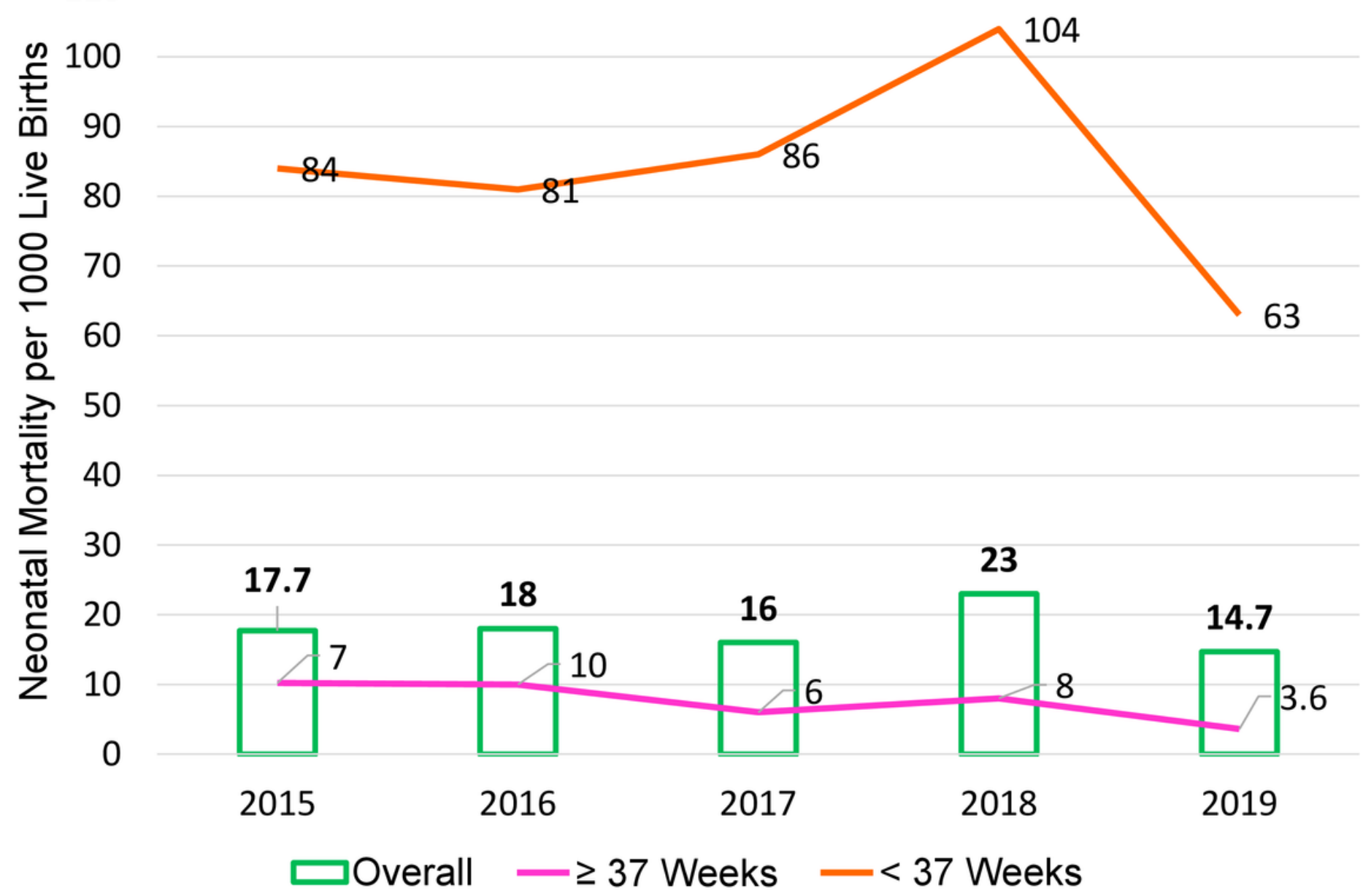

Figure 1

Overall Neonatal Mortality and for newborns $<37$ and $\geq 37$ weeks per 1000 live births for years 20152019. * Represent significant reduction in mortality for newborns $\geq 37$ weeks comparing 2015 and 2019 


\section{0}

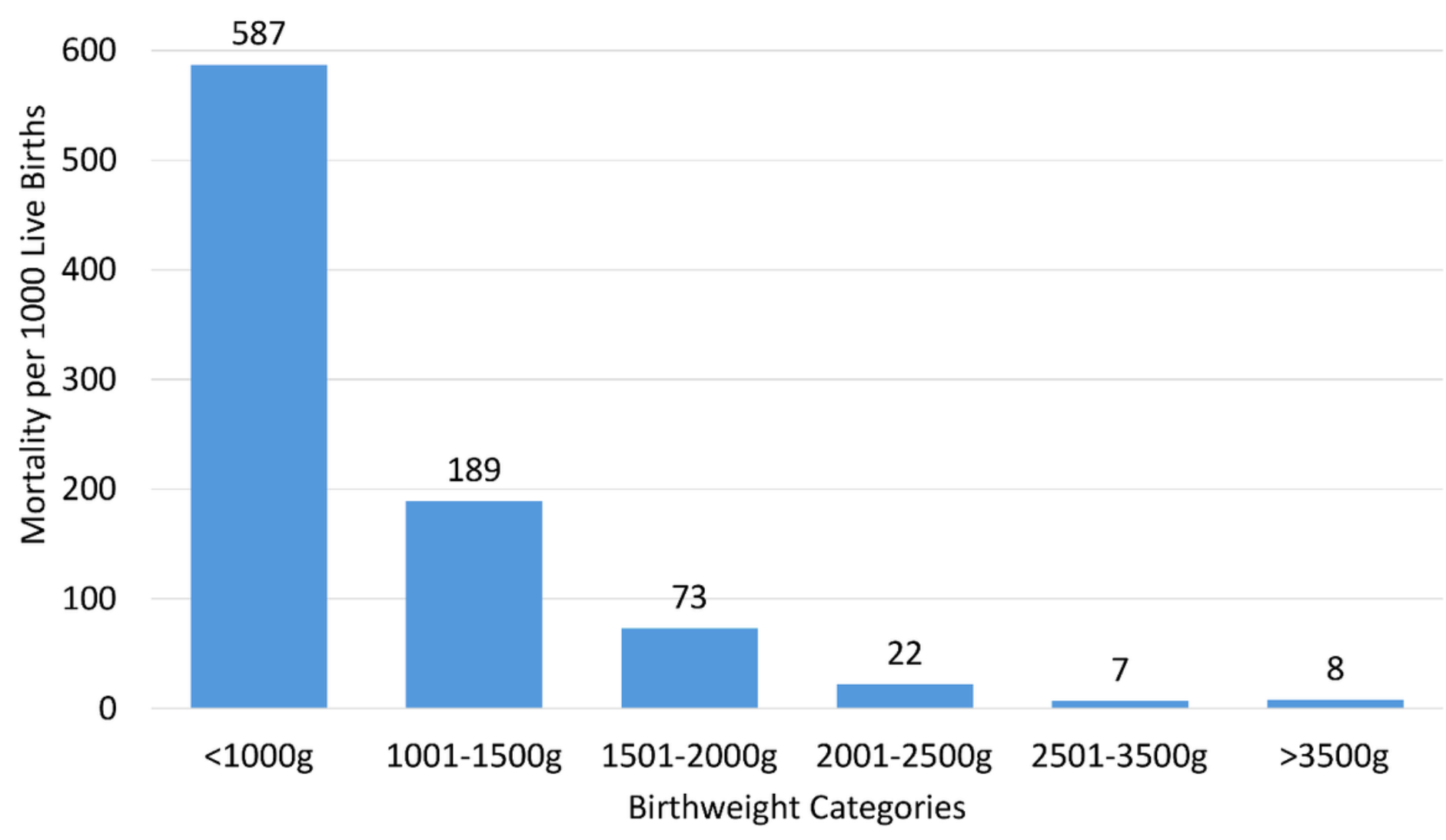

Figure 2

Mortality per 1000 live births as a function of birth weight. 


\section{Mortality per 1000 live births as a Function of Gestational Age}

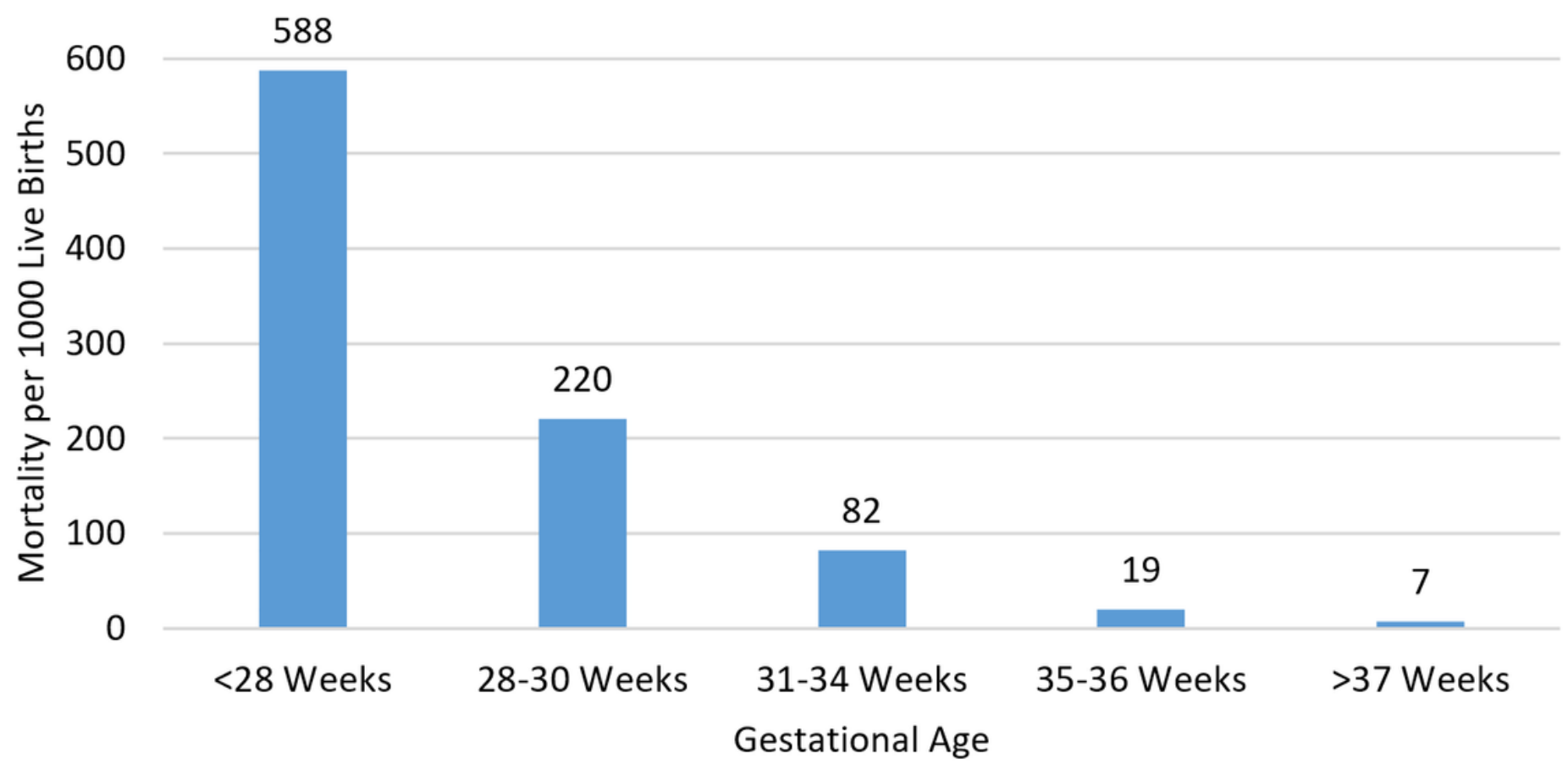

Figure 3

Mortality per 1000 live births as a function of gestational age. 